\title{
Article \\ MXene Core-Shell Nanosheets: Facile Synthesis, Optical Properties, and Versatile Photonics Applications
}

\author{
Yunjia Wang ${ }^{\dagger}$, Shunxiang Liu ${ }^{\dagger}$, Feng Zhu ${ }^{\dagger}$, Yiyu Gan and Qiao Wen * (1) \\ Key Laboratory of Optoelectronic Devices and Systems of Ministry of Education and Guangdong Province, \\ College of Physics and Optoelectronic Engineering, Shenzhen University, Shenzhen 518060, China; \\ wangyunjia@szu.edu.cn (Y.W.); 2150190124@email.szu.edu.cn (S.L.); 1160713978@szu.edu.cn (F.Z.); \\ 2151190226@email.szu.edu.cn (Y.G.) \\ * Correspondence: wenqiao@szu.edu.cn \\ † These authors contributed equally to this work.
}

check for updates

Citation: Wang, Y.; Liu, S.; Zhu, F.; Gan, Y.; Wen, Q. MXene Core-Shell Nanosheets: Facile Synthesis, Optical Properties, and Versatile Photonics Applications. Nanomaterials 2021, 11, 1995. https://doi.org/10.3390/ nano11081995

Academic Editor: Filippo Giannazzo

Received: 20 June 2021

Accepted: 21 July 2021

Published: 3 August 2021

Publisher's Note: MDPI stays neutral with regard to jurisdictional claims in published maps and institutional affiliations.

Copyright: (c) 2021 by the authors. Licensee MDPI, Basel, Switzerland. This article is an open access article distributed under the terms and conditions of the Creative Commons Attribution (CC BY) license (https:// creativecommons.org/licenses/by/ $4.0 /)$.

\begin{abstract}
In recent years, the transition metal carbonitrides(MXenes) have been widely applied to photoelectric field, and better performance of these applications was achieved via MXene complex structures. In our work, we proposed a MXene core-shell nanosheet composed of a $\mathrm{Ti}_{2} \mathrm{C}(\mathrm{MXene})$ phase and gold nanoparticles, and applied it to mode-locked and single-frequency fiber laser applications. The optoelectronic results suggested that the performances of these two applications were both improved when MXene core-shell nanosheets were applied. As a result, we obtained a mode-locking operation with $670 \mathrm{fs}$ pulses, and the threshold pump power reached to as low as $20 \mathrm{~mW}$. Besides, a single-frequency laser with the narrowest linewidth of $\sim 1 \mathrm{kHz}$ is also demonstrated experimentally. Our research work proved that MXene core-shell nanosheets could be used as saturable absorbers (SAs) to promote versatile photonic applications.
\end{abstract}

Keywords: 2D material; core-shell structure; mode-locked; single frequency; fiber laser

\section{Introduction}

Over the past decade, researches on two-dimensional (2D) materials [1] have drawn much attention, and these 2D materials included transition metal dichalcogenides (TMDs) [2], semiconductors [3,4], and insulators [5]. Due to the strong interaction with lightwaves, more and more applied fundamental researches of 2D materials have concentrated in versatile photonic applications [6]. Nonlinear optical characteristic was one of the most important properties of 2D materials. By taking full advantage of the unique nonlinear optical characteristic, 2D materials have been widely applied to laser technology, laser processing [7], laser displays [8], photodetectors [9], laser facilities [10], and medical treatment [11]. Graphene, as the earliest discovered 2D materials, possesses a zero band gap and has been proved to achieve good nonlinear optical characteristics. But the low absorption coefficient and low damage threshold have limited its development [12]. BP, as a tunable band gap semiconductor, has been demonstrated to exhibit remarkable anisotropy, high carrier mobility, and good stability with a layered structure [13]. However, when it was applied to photonics researches, the exfoliation of few-layer nanosheet structure, seriously decreased the stability of BP and further restricted its application in photonics.

To our best knowledge, MXenes, as one of the novel 2D materials, have been reported to be achieved from the $\operatorname{MAX}(\mathrm{M}=$ transition metal, $\mathrm{A}=\mathrm{Al}, \mathrm{X}=\mathrm{C}, \mathrm{N})$ phase. Because of the treatment by HF solution, the surface of MXenes is rich in functional groups [14], such as $-\mathrm{F},-\mathrm{O}$, and $-\mathrm{OH}$ group. Such surface groups have promised MXene materials a flexible surface modification [15]. Moreover, the layered structure has ensured MXene materials tunable properties [16,17], and made them more potential in photoelectronics [18], photocatalysis [19], and energy storage [20]. Our team has demonstrated the nonlinear 
optical characteristics of MXenes in erbium-doped fiber (EDF) lasers. Based on the functional groups of MXene materials and our previous work, we have further promoted the performance of MXenes by fully utilizing the advantages of MXene@gold core-shell nanosheets.

As we known, MXene core-shell nanostructures usually consist of MXene materials and other materials via the effect of functional groups. By applying core-shell nanostructures, the photoelectric properties of MXene materials were demonstrated to be modified, such as absorption enhancement or shiftness of the absorption peak [21]. If MXene materials are enclosed by nanometal materials, or by other materials that possess collective free electrons, such as gold nanoparticles or silver nanoparticles, then the optical characteristics are expected to be enhanced due to surface plasmon effect [22]. For example, MXene@gold core-shell nanocomposites have been reported to exhibit highly efficient catalysis ability, and effectively enhanced the second biological window [23,24]. These studies suggested that the strong photoelectronic interaction is fully utilized by MXene@gold core-shell structure, and excellent performance is achieved. However, the surface plasmon effect of metal nanoparticles on MXene materials has not been deeply demonstrated, application of the MXene@gold nanostructure to promote the performance in photonics technology has seldom been reported, and its improvement mechanism has not yet been explored [25].

To our best knowledge, ultrafast fiber lasers (UFFLs) and single-frequency fiber lasers (SFFLs) are two important fiber lasers in our daily life and industrial manufacturing. The UFFL with an ultrashort pulse width is a significant component in fiber communications [26], micromachining [27], and medical surgery [28]. Hence, researchers have devoted themselves to improving the characteristics of UFFLs, which included a lower lasing threshold, an ultrashort pulse width, a high peak power, and a high repetition frequency. In addition, a stable SFFL with narrow linewidth and low noise is an ideal candidate for coherent optical communications [29], precise optical sensing [30], gravitational wave detection [31], and lidar [32]. It should be noted that, the narrow linewidth of SFFL has been eagerly pursued, and the reason was maily ascribed to the urgent need of high-precision sensing systems [33]. Recently, Ning Xu et al. have synthesized MXene $\left(\mathrm{Ti}_{3} \mathrm{C}_{2} \mathrm{Tx}\right)$ quantum dots from few-layer MXene materials, and applied it to UFFLs and SFFLs [34]. The results suggested that better nonlinear optics was achieved due to quantum effect, and indicated that the laser characteristics can be optimized by improving the optical nonlinear response of MXenes materials.

In our work, $\mathrm{Ti}_{2} \mathrm{C} @ \mathrm{Au}$ core-shell nanosheets were prepared and employed as a saturable absorber (SA) to construct an UFFL and a SFFL. Compared with the UFFL and SFFL, which employed $\mathrm{Ti}_{2} \mathrm{C}$ nanosheets as a SA [35], the laser characteristics of both UFFL and SFFL were conspicuously promoted. The results suggested that the UFFL based on $\mathrm{Ti}_{2} \mathrm{C} @ \mathrm{Au}$ core-shell nanostructure has a lasing threshold as low as $20 \mathrm{~mW}$, and the SFFL in this work has a laser linewidth as narrow as $1 \mathrm{kHz}$, which were the best performances among the relevent lasers based on MXenes. It indicated that the $\mathrm{Ti}_{2} \mathrm{C} @ \mathrm{Au}$ core-shell nanostructure was a potential material for achieving low threshold, low noise, and narrow linewidth in EDF-SFFLs. Our study provided insight into promoting MXene materials in fiber laser applications.

\section{Results and Discussions}

\subsection{Fabrication and Characterization of $\mathrm{Ti}_{2} \mathrm{C} @ \mathrm{Au}$}

In Brief, $\mathrm{Ti}_{2} \mathrm{C} @ \mathrm{Au}$ nanostructures were synthesized from $\mathrm{Ti}_{2} \mathrm{C}$ materials, which were fabricated from the $\mathrm{Ti}_{2} \mathrm{AlC}$ phase. First, the purchased $\mathrm{Ti}_{2} \mathrm{AlC}$ solid phase was dissolved in $\mathrm{HF}$ solution, and then ultrasonicated to achieve a few-layer $\mathrm{Ti}_{2} \mathrm{C}$ solution. Second, the $\mathrm{Ti}_{2} \mathrm{C}$ solution was centrifugated at $3000 \mathrm{r} / \mathrm{min}$ for $2 \mathrm{~min}$ to obtain small $\mathrm{Ti}_{2} \mathrm{C}$ particles. Subsequently, $\mathrm{HAuCl}_{4}$ crystals were dissolved in deionized water and then combined with the $\mathrm{Ti}_{2} \mathrm{C}$ particle dispersion in a beaker. The redox reaction of $\mathrm{HAuCl}_{4}$ and $\mathrm{Ti}_{2} \mathrm{C}$ particles was conducted at $40{ }^{\circ} \mathrm{C}$ for $30 \mathrm{~min}$ to prepare core-shell nanostructures. After 
the reaction process, the composites were centrifuged and dispersed in an isopropanol solution before use.

The flowchart in Figure 1 shows the preparation process of $\mathrm{Ti}_{2} \mathrm{C} @ \mathrm{Au}$ core-shell nanostructure. The reaction between MXene materials and $\mathrm{Au}^{3+}$ can be expressed by the following equation:

$$
\mathrm{Ti}_{2} \mathrm{CF}_{\mathrm{x}}(\mathrm{OH})_{\mathrm{y}}+3 \delta \mathrm{e}^{-}+\delta \mathrm{Au}^{3+} \rightarrow \mathrm{Ti}_{2} \mathrm{CF}_{\mathrm{x}}(\mathrm{OH})_{\mathrm{y}}+\delta \mathrm{Au}
$$

In Equation (1), $\mathrm{Ti}_{2} \mathrm{CF}_{\mathrm{x}}(\mathrm{OH})_{\mathrm{y}}$ represented $\mathrm{Ti}_{2} \mathrm{C}$ (MXene) materials, whose surface showed -F and -OH groups, $\mathrm{HAuCl}_{4}$ crystal could be dissolved into $\mathrm{Au}^{3+}$ in solution. During the reaction, a mounts of $\mathrm{Au}^{3+}$ were reduced to gold nanoparticle and deposited onto $\mathrm{Ti}_{2} \mathrm{C}$ (MXene) materials when reacted with $\mathrm{Ti}_{2} \mathrm{CF}_{\mathrm{x}}(\mathrm{OH})_{\mathrm{y}}$. In our preparation experiment, the solvent concentration and the usage was strictly kept the same. The concentration of the $\mathrm{Ti}_{2} \mathrm{C}$ material and the $\mathrm{Ti}_{2} \mathrm{C} @ \mathrm{Au}$ core-shell nanostructure, were both adjusted to $3 \mathrm{mg} / \mathrm{mL}$ with isopropanol.

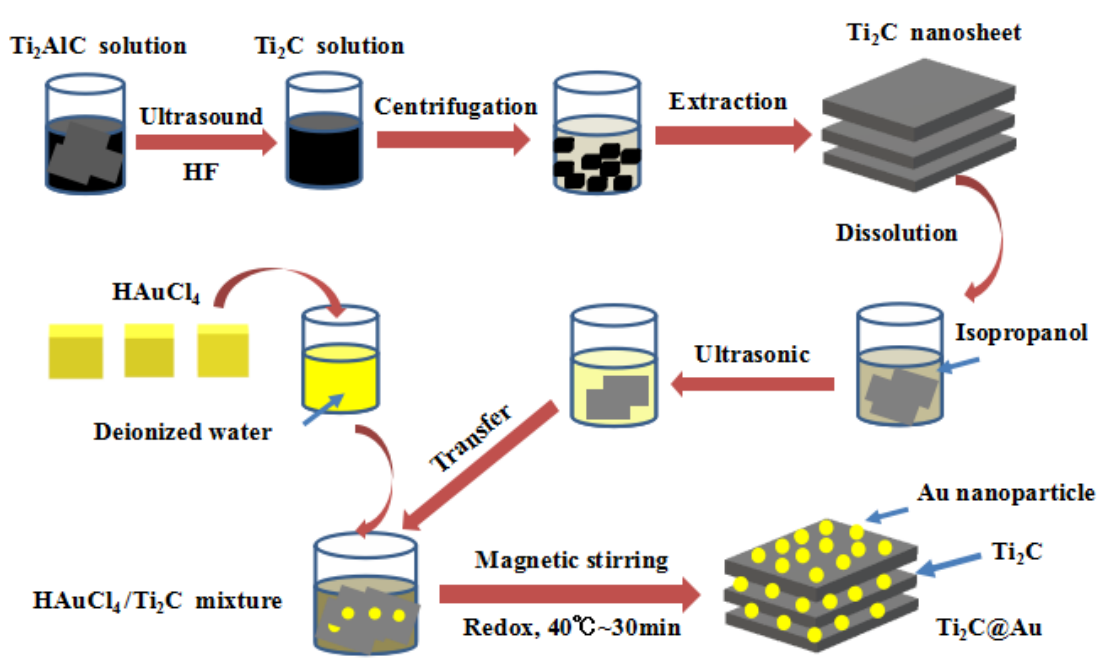

Figure 1. Schematic illustration of the $\mathrm{Ti}_{2} \mathrm{C} @ \mathrm{Au}$ nanostructure preparation.

Figure 2 shows the scanning electronic microscopy (SEM) characterization and transimission electronic microscopy (TEM) characterization of the prepared $\mathrm{Ti}_{2} \mathrm{C}$ material and $\mathrm{Ti}_{2} \mathrm{C} @ \mathrm{Au}$ core-shell nanostructure.

(a)

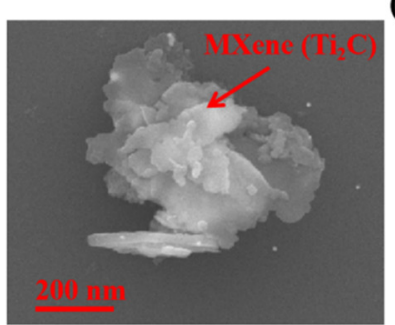

(d)

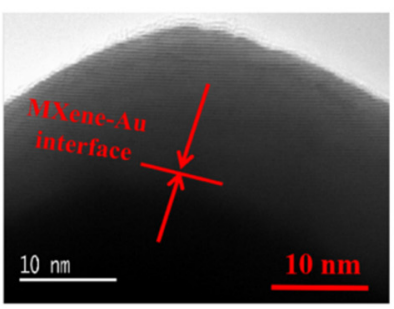

(b)

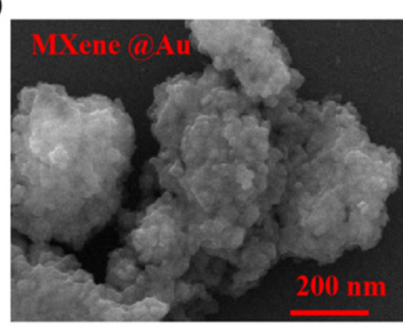

(e)

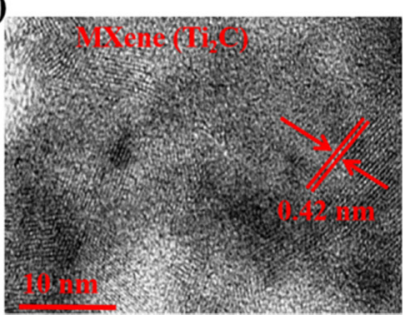

(c)

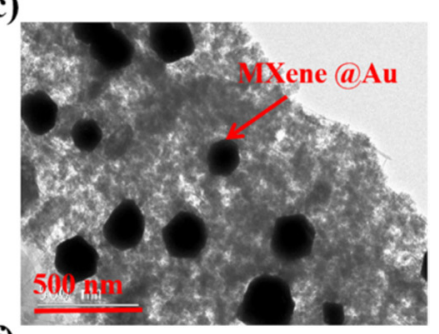

(f)

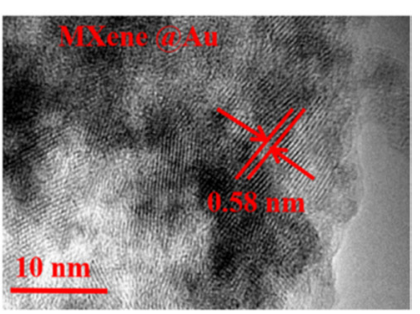

Figure 2. (a) SEM image of $\mathrm{Ti}_{2} \mathrm{C}$ nanostructure; (b) SEM image of $\mathrm{Ti}_{2} \mathrm{C} @ \mathrm{Au}$ nanostructure; (c,d)TEM image of $\mathrm{Ti}_{2} \mathrm{C} @ \mathrm{Au}$ nanostructure; $(\mathbf{e}, \mathbf{f}) \mathrm{Ti}_{2} \mathrm{C}$ nanostructure and $\mathrm{Ti}_{2} \mathrm{C} @ \mathrm{Au}$ nanostructure analyzed by resolution TEM. 
Figure 2a shows the SEM image of $\mathrm{Ti}_{2} \mathrm{C}$ material, which exhibited a morphology of layer structure, while Figure $2 \mathrm{~b}$ shows the SEM image of $\mathrm{Ti}_{2} \mathrm{C} @ \mathrm{Au}$ core-shell nanostructure, which presented densitive spots deposited on the $\mathrm{Ti}_{2} \mathrm{C}$ materials. Figure $2 \mathrm{c}-\mathrm{f}$ shows the TEM images of the prepared $\mathrm{Ti}_{2} \mathrm{C}$ materials and the $\mathrm{Ti}_{2} \mathrm{C} @ \mathrm{Au}$ core-shell nanostructure, to further analyze the transformation from the $\mathrm{Ti}_{2} \mathrm{C}$ material to the $\mathrm{Ti}_{2} \mathrm{C} @ \mathrm{Au}$ nanostructure. As depicted, a core-shell-like nanostructure with a shell thickness of approximately $15 \mathrm{~nm}$ was found, and the crystal lattice distance was enlarged from 0.42 to $0.58 \mathrm{~nm}$ when the $\mathrm{Ti}_{2} \mathrm{C}$ material was transformed into the $\mathrm{Ti}_{2} \mathrm{C} @ \mathrm{Au}$ core-shell nanostructure.

Figure 3 shows the $\mathrm{X}$-ray photoelectronic spectrum (XPS) of $\mathrm{Ti}_{2} \mathrm{C} @ \mathrm{Au}$ core-shell nanostructure for further analyzing. As depicted, the binding energy intensity was enhanced when the spots deposited on the $\mathrm{Ti}_{2} \mathrm{C}$ material. From Figure $3 \mathrm{~d}$, we confirmed the spots to be gold nanoparticles with the binding energies of $83 \mathrm{eV}$ and $87 \mathrm{eV}$. In addition, the titanium elemental analysis exhibited in Figure $3 \mathrm{~b}$, shows the binding energy intensity of $\mathrm{Ti}_{2} \mathrm{C}$ material is remarkly enhanced with densitive coverage of gold nanoparticles. A similar phenomenon was found for carbon element, which is shown in Figure 3c. These results indicated that the outer environment of $\mathrm{Ti}_{2} \mathrm{C}$ materials was modified when covered by gold nanoparticles [36-38].

(a)

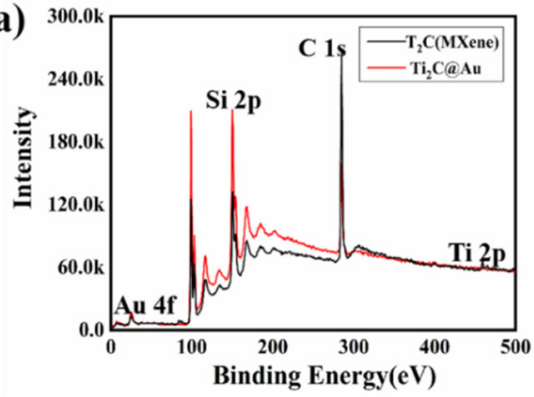

(c)

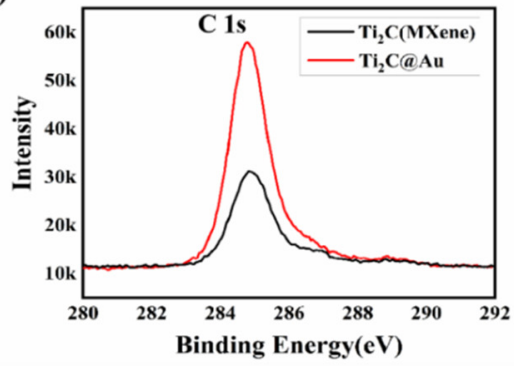

(b)

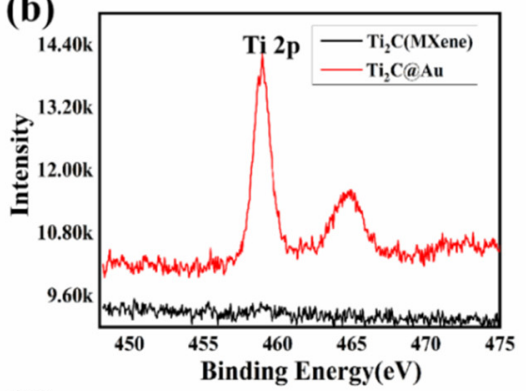

(d)

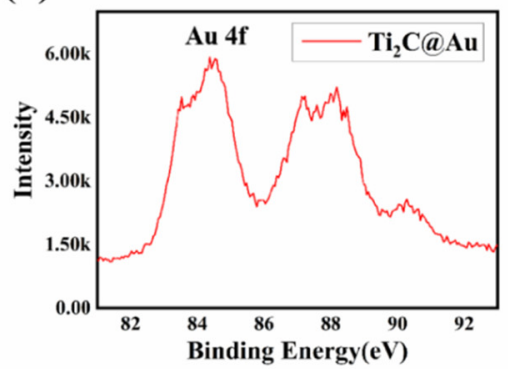

Figure 3. (a) XPS analysis of the $\mathrm{Ti}_{2} \mathrm{C}$ material and $\mathrm{Ti}_{2} \mathrm{C} @ \mathrm{Au}$ nanostructure; (b) titanium elemental analysis; (c) carbon elemental analysis; (d) gold elemental analysis.

Figure 4a shows the absorption spectra of $\mathrm{Ti}_{2} \mathrm{C}$ materials and $\mathrm{Ti}_{2} \mathrm{C} @ \mathrm{Au}$ nanostructure. As depicted, $\mathrm{Ti}_{2} \mathrm{C}$ material and $\mathrm{Ti}_{2} \mathrm{C} @ \mathrm{Au}$ nanostructure both exhibited a broad absorption range from 400 to $2000 \mathrm{~nm}$. It should be noted that there were six optical peaks appeared in the absorption spectra of $\mathrm{Ti}_{2} \mathrm{C}$ materials, which were respectively located around 900, $1015,1470,1590$, and $1710 \mathrm{~nm}$. It indicated that abundant energy level was achieved for the prepared $\mathrm{Ti}_{2} \mathrm{C}$ material, however, when the gold nanoparticles deposited on $\mathrm{Ti}_{2} \mathrm{C}$ material, the absorption peak of $1710 \mathrm{~nm}$ was significantly enhanced. To our best knowledge, gold nanoparticles hardly reacted with the $\mathrm{Ti}_{2} \mathrm{C}$ materials via chemical interaction, so we establish that the absorption enhancement originated from the physical interaction when excited by an incident with wavelength around $1710 \mathrm{~nm}$. Owing to the collective oscillation of free electrons, electromagnetic field that local around gold nanoparticles was considered to be formed, and attributed to the absorption enhancement of $\mathrm{Ti}_{2} \mathrm{C}$ material. 
(a)

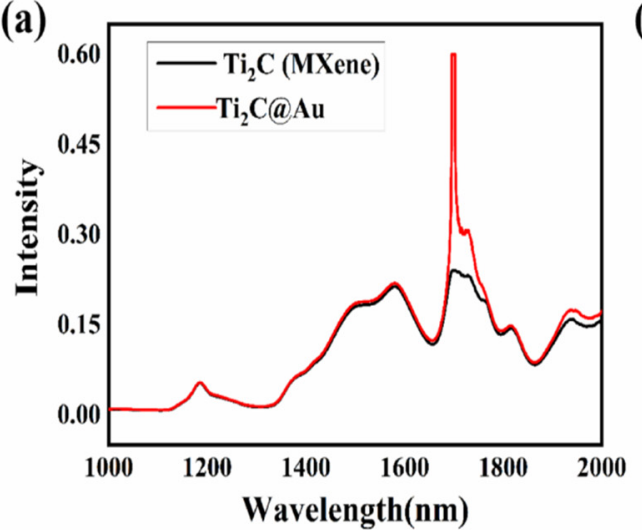

(b)

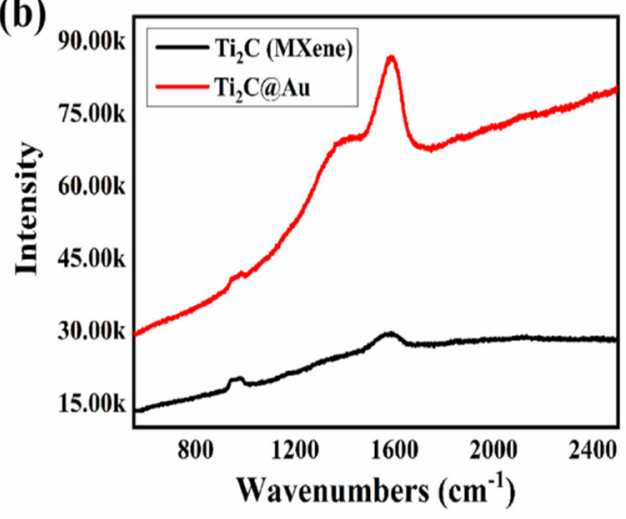

Figure 4. (a) Absorption spectra of equal amounts of $\mathrm{Ti}_{2} \mathrm{C}$ materials and $\mathrm{Ti}_{2} \mathrm{C} @ \mathrm{Au}$ core-shell nanostructure; (b) Raman spectrum of $\mathrm{Ti}_{2} \mathrm{C}$ materials and $\mathrm{Ti}_{2} \mathrm{C} @ \mathrm{Au}$ core-shell nanostructure.

As we know, the Raman scattering signals of most molecules could be enhanced due to the electromagnetic field excitation. So we applied the Raman spectrum to demonstrate the field-enhancemnet effect of $\mathrm{Ti}_{2} \mathrm{C} @ \mathrm{Au}$ nanostructure, whose result is shown in Figure $4 \mathrm{~b}$; $\mathrm{Ti}_{2} \mathrm{C}$ materials was measured for a comparison. As depicted, we infered the characterized peak that located around $1050 \mathrm{~cm}^{-1}$ originated from the vibration of carbon atom, and another peak that exhibited around $1600 \mathrm{~cm}^{-1}$ was due to the vibration of -OH group. However, when the gold nanoparticles deposited onto $\mathrm{Ti}_{2} \mathrm{C}$ material, significant enhancement was observed of such characterized peaks. These results suggested that photoelectric interaction was fully utilized when gold nanoparticle and $\mathrm{Ti}_{2} \mathrm{C}$ material were assembled together in such a complex structure, and attributed to the field enhancement effect.

\subsection{Optical Nonlinearity Characteristics}

Figure 5 shows a balanced twin-detector measurement system to study the nonlinear optical characteristics of the fabricated $\mathrm{Ti}_{2} \mathrm{C} @ \mathrm{Au}-\mathrm{SA}$. The seed source is a homemade erbium-doped fiber laser with a pulse duration of $600 \mathrm{fs}$ and a repetition rate of $8.13 \mathrm{MHz}$. After the measurement, we found that the fabricated $\mathrm{Ti}_{2} \mathrm{C} @ \mathrm{Au}-\mathrm{SA}$ has a modulation depth of $6.6 \%$, a saturation intensity of $17.96 \mathrm{GW} / \mathrm{cm}^{2}$, and the corresponding non-saturable loss of $18.9 \%$.

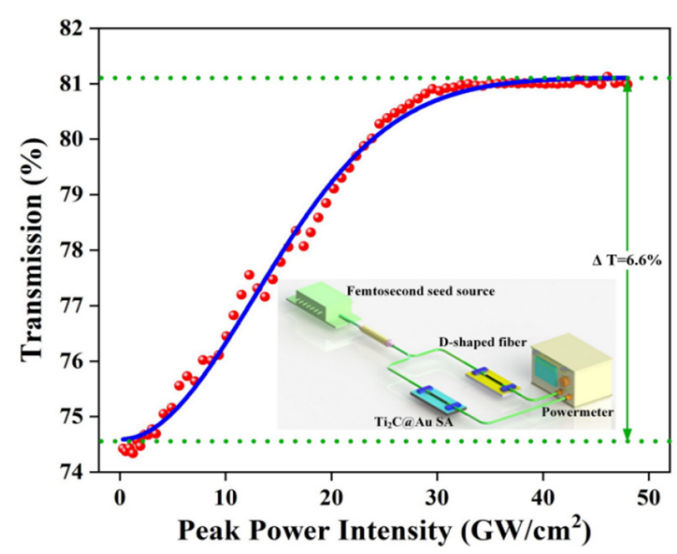

Figure 5. Nonlinear transmittance of the $\mathrm{Ti}_{2} \mathrm{C} @ \mathrm{Au}-\mathrm{SA}$ as a function of peak power intensity.

\subsection{Mode-Locked Fiber Laser}

To analyze the performance of $\mathrm{Ti}_{2} \mathrm{C} @ \mathrm{Au}$ in erbium-doped fiber laser, the $\mathrm{Ti}_{2} \mathrm{C} @ \mathrm{Au}$ saturable absorbers are transferred to an all-fiber laser setup, and pumped by a $980 \mathrm{~nm}$ laser diode with a maximum power of $750 \mathrm{~mW}$ via a wavelength-division multiplexer, as shown in the Figure 6. 


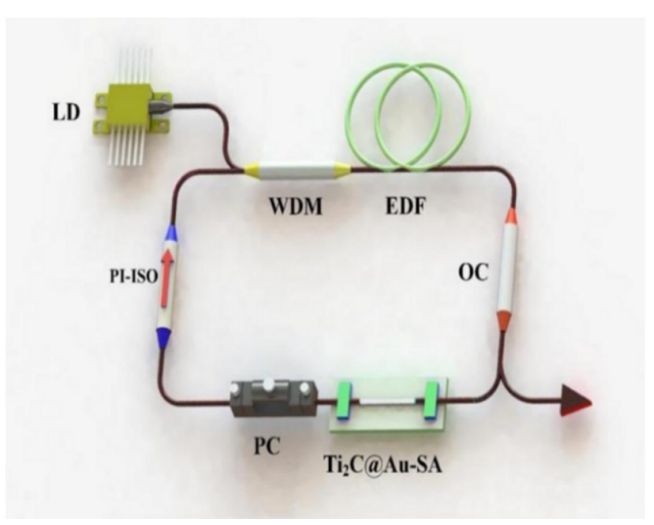

Figure 6. Configuration of the pulsed laser or ultra-short pulsed laser based on $\mathrm{Ti}_{2} \mathrm{C} @ \mathrm{Au}$. LD: laser diode. WDM: wavelength division multiplexer. EDF: erbium-doped fiber. OC: output coupler. $\mathrm{Ti}_{2} \mathrm{C}$ @Au-SA: $\mathrm{Ti}_{2} \mathrm{C} @ \mathrm{Au}$ saturable absorber. PC: polarization controller. PI-ISO: polarization independent isolator.

The characteristics of the stable femtosecond pulse results are shown in Figure 7a-d. As depicted, the stable mode-locked regime was obtained when the pump power was larger than $20 \mathrm{~mW}$, while, to our best knowledge, the obtained mode-locking threshold is the lowest among the MXenes at a wavelength of 1.55 um (see Table S1). Figure 7a displays the mode-locked pulse train. The time interval between the two pulses was $117.6 \mathrm{~ns}$, which corresponded to $8.5 \mathrm{MHz}$ repetition rate. Figure $7 \mathrm{~b}$ shows the optical spectrum was centered at $1560 \mathrm{~nm}$ with mode-locked pulses and a 3-dB spectral width of $3.2 \mathrm{~nm}$.

(a)

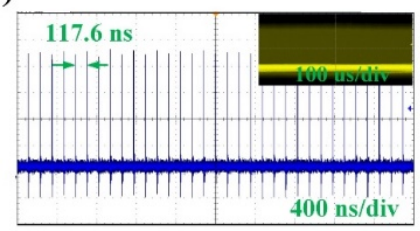

(c)

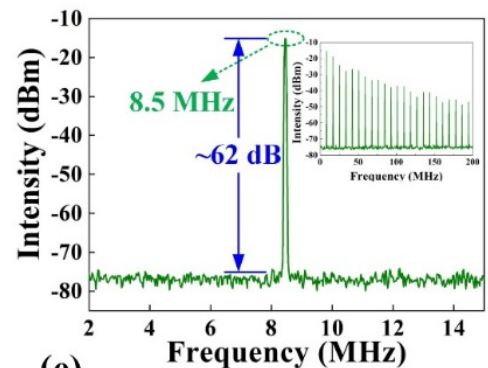

(e)

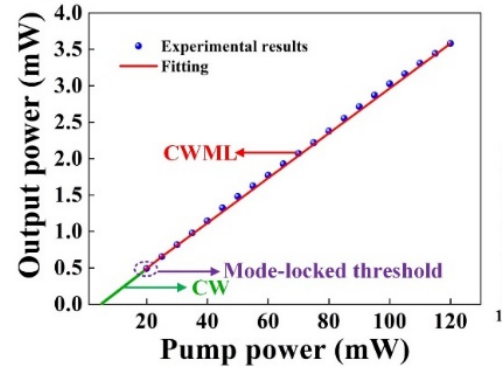

(b)
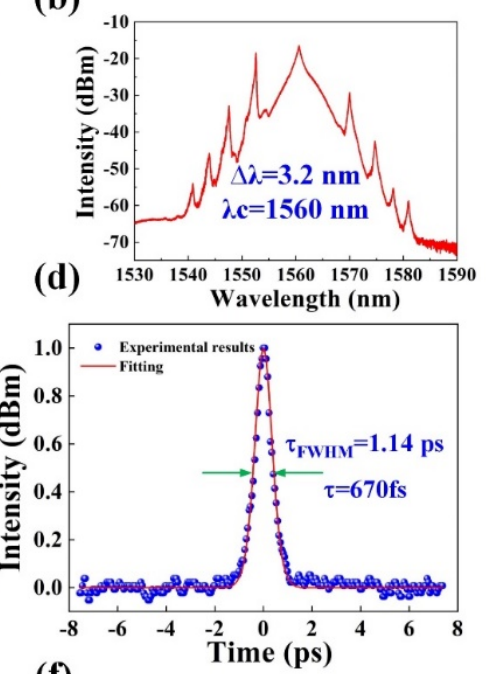

(f)

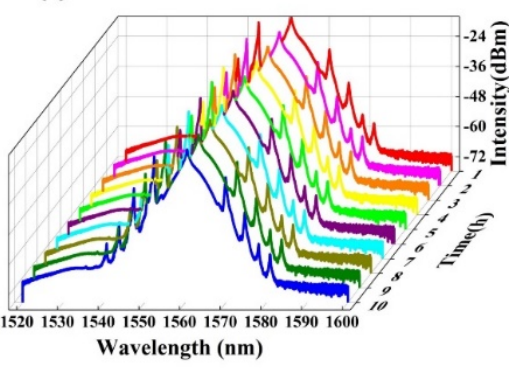

Figure 7. Typical mode-locking characteristics. (a) Pulse train. (b) Optical spectrum. (c) Radio frequency spectrum (inset: the wideband RF spectrum). (d) Autocorrelation trace. (e) Variation of the output power with respect to the pump power. (f) Optical spectra measurements at $1 \mathrm{~h}$ intervals over $10 \mathrm{~h}$. 
Figure 7c presents a strong signal peak with a mode-locked repetition rate of $8.5 \mathrm{MHz}$, and the signal to noise ratio (SNR) of about $62 \mathrm{~dB}$. The autocorrelation trace of corresponding mode-locked pulse is shown in Figure $7 \mathrm{~d}$. When the sech ${ }^{2}$ function was used to fit the measured pulse autocorrelation trace, the estimated pulse duration was $670 \mathrm{fs}$ with a time-bandwidth product (TBP) of 0.54 . Figure 7e presents the relationship between average output power and pump power, and it shows an excellent linear relationship with a slope efficiency of $3.08 \%$. In our experiment, the laser was operated in continuous wave (CW) regime when the pump power was increased to $5 \mathrm{~mW}$, as the pump power further increased to the threshold of $20 \mathrm{~mW}$, stable continuous wave mode lock (CWML) was achieved. Figure $7 \mathrm{f}$ shows the pulse spectrum that applied the same material solution evolved over $10 \mathrm{~h}$, which indicated that higher stability of the Erbium-doped femtosecond fiber laser was obtained. For a convenient comparison, we listed the properties of EDFs based on 2D materials in Table S1, which was shown in the supporting information.

To explain the better performance for mode-locked fiber laser when applied the $\mathrm{Ti}_{2} \mathrm{C} @ \mathrm{Au} \mathrm{SA}$, we owned the reason to the surface plasmon effect that originated from the gold nanoparticles, which resulted in the enhancement of nonlinear optics [39].

Figure 8 shows the schematic diagram illustration of the mode-locking laser by applied $\mathrm{Ti}_{2} \mathrm{C} @ \mathrm{Au}$ core-shell nanostructures. As depicted, a mount of gold nanoparticles deposited on the surface of $\mathrm{Ti}_{2} \mathrm{C}$ materials, and excited by laser source with wavelength of $1500 \mathrm{~nm}$, then collective electrons are aroused and form oscillation around the interface between gold nanoparticle and $\mathrm{Ti}_{2} \mathrm{C}$ materials, resulting in local electromagnetic field enhancement [40]. Under the affection of electromagnetic filed, the electronic cloud of MXene core-shell nanostructures is distorted, and the $\mathrm{Ti}_{2} \mathrm{C}$ material molecules trend to reorient and lead to a change of electronic density, as well as the variation of refractivity [41]. Thus, the strong light wave that coupled into fiber laser, can be effectively modulated via the interaction with $\mathrm{Ti}_{2} \mathrm{C} @ \mathrm{Au}$ core-shell nanostructures. That is, the photonic mode which is harmonic with the polarization direction, is effectively enhanced, while those that are not harmonic with the polarization direction weaken [42].
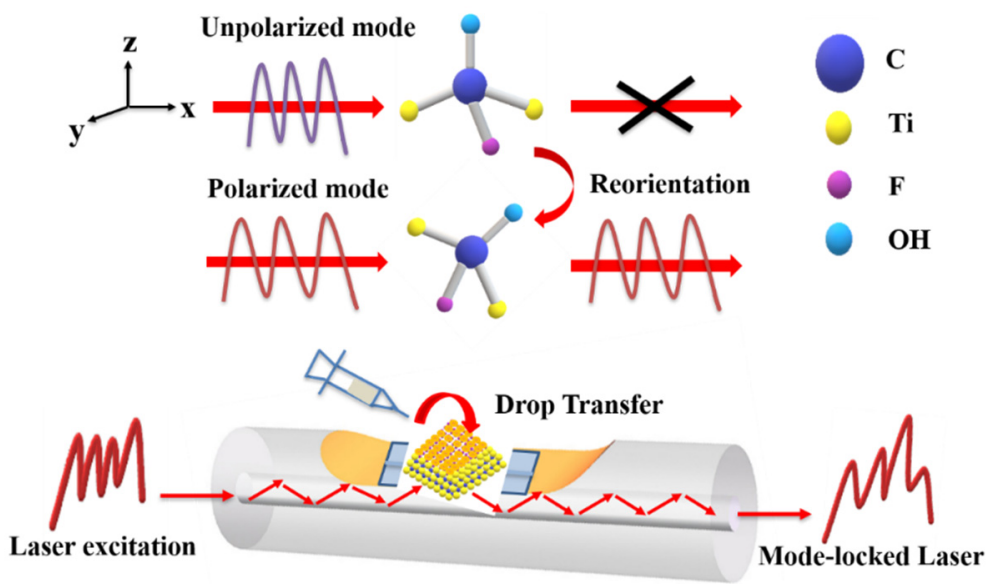

Figure 8. Schematic illustration of mode-locked fiber laser by using MXene core-shell nanostructures.

To our best knowledge, nonlinear absorption optic of dielectric, is correlated with the modification of refractive index, which is proportional to the square of electric field.

Here, the nonlinear absorption coefficient of $\mathrm{Ti}_{2} \mathrm{C} @ \mathrm{Au}$ nanostructures that applied to fiber laser is given by [43]:

$$
\alpha_{\text {non,G }}=\frac{\alpha_{0}}{1+\mathrm{I}_{\mathrm{e}, \mathrm{t}} / \mathrm{I}_{\mathrm{e}, \mathrm{sat}}} \rightarrow \mathrm{I}_{\mathrm{e}, \mathrm{t}}=\mathrm{I}_{\mathrm{e}, \mathrm{sat}}\left(\frac{\alpha_{0, \mathrm{G}}}{\alpha_{\text {non,G }}}-1\right)
$$

where $\alpha_{0, G}$ is the nonlinear absorption component, $I_{e, t}$ represents the evanescent-wave intensity, and $\mathrm{I}_{\mathrm{e} \text {,sat }}$ represents the saturable intensity of $\mathrm{Ti}_{2} \mathrm{C} @ \mathrm{Au}$ nanostructures. The 
evanescent-wave within the hole-cladding region of the fiber laser, was interfered by the evanescent-wave that originated from the gold nanoparticles, and the evanescent-wave intensity exponentially decayed with the radial distance $(\mathrm{x})$ away from the core/cladding interface. We described the evanescent-wave intensity by following equation [44]:

$$
\mathrm{I}_{\mathrm{e}, \mathrm{sat}}=\mathrm{I}_{0} \mathrm{e}^{-2 \beta \mathrm{x}}
$$

where $I_{0}$ and $\beta$ are respectively the pulse intensity of intracavity and the extinction coefficient factor. With the assistance of $\mathrm{Ti}_{2} \mathrm{C} @ \mathrm{Au}$ nanostructures, the extinction coefficient factor is expressed by Equation (4) [45]:

$$
\beta=\frac{2 \pi n_{c}}{\lambda}\left(\frac{\sin ^{2} \theta}{\left(\frac{n_{c}}{n_{i}}\right)^{2}}-1\right)^{2}
$$

where $\mathrm{n}_{\mathrm{i}}$ is the core refractive index, and $\mathrm{n}_{\mathrm{c}}$ is the effective cladding refractive index. In our work, the core is acted by $\mathrm{Ti}_{2} \mathrm{C}$ materials, and the cladding are gold nanoparticles. To our best knowledge, gold nanoparticle possesses a higher refractive index than $\mathrm{Ti}_{2} \mathrm{C}$ materials, so the value of $\frac{n_{c}}{n_{i}}$ is larger than 1 , and the extinction coefficient factor $\beta$ is negative. According to Equations (2) and (3), the $I_{e, \text { sat }}$ and $\alpha_{0, G}$ are positively increased compared to the pure MXene materials, which coincided with the P-scan measurement of the $\mathrm{Ti}_{2} \mathrm{C} @ \mathrm{Au}$ nanostructures. It indicated that the nonlinear absorption is effectively improved by gold nanoparticles, and contributed to the lower threshold output of ultrashort pulse.

\subsection{Single Frequency Fiber Laser}

To further understand the nonlinear optic enhancement effect by using $\mathrm{Ti}_{2} \mathrm{C} @ \mathrm{Au}$ core-shell nanostructures, the $\mathrm{Ti}_{2} \mathrm{C} @ \mathrm{Au}$ was applied as a SA to single frequency fiber laser (SFFL). Figure 9 shows the experimental schematic of this SFFL which included a seed laser and an amplifier.

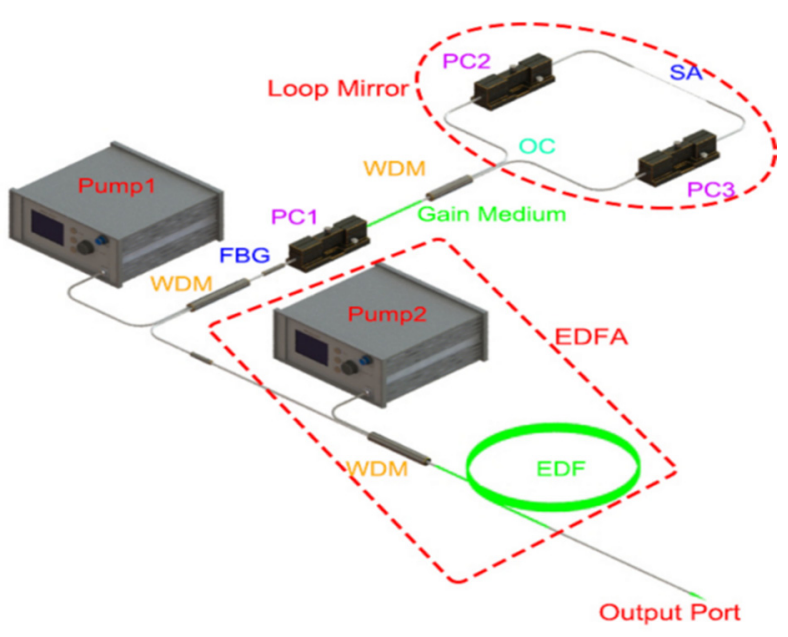

Figure 9. Experimental schematic of SFFL based on LCLM embedded a SA.

Pump 1 was launched into the laser cavity through a fiber bragg grating (FBG, reflection of $57 \%$ at $1549.65 \mathrm{~nm}, 3 \mathrm{~dB}$ bandwidth of $0.036 \mathrm{~nm}$ ) via a $1 \times 2$ wavelength division multiplexer (WDM, 980/1550 nm). A length of $0.3 \mathrm{~m}$ single mode EDF (peak absorption of $17 \mathrm{~dB} / \mathrm{m}$ at $1530 \mathrm{~nm}$ ) was severed as the gain medium. In purpose of eliminating the effect on the loop mirror by the residual pump, another WDM $(1 \times 2.980 / 1550 \mathrm{~nm})$ was spliced to the EDF. On the end of the cavity, the loop mirror that connected the WDM by an optical coupler(OC, 50/50), was worked as a high reflectivity mirror to bring laser beam back. A section of tapered fiber, with a length of $\sim 3 \mathrm{~cm}$ and a waist diameter of $\sim 10 \mu \mathrm{m}$, was embedded into the loop mirror to release the optical evanescent filed. To optimize the 
reflection of the loop mirror, a polarization controller (PC2 and PC3) was set to adjust the polarization of the counter-propagation beam. As we know, the spatial hole buring (SHB) effect holds when two laser beams are encountered in the cavity. Thus the PC1, which was between FBG and gain medium, was employed to restrain this effect [46]. It should be noted that the total length of the cavity was $\sim 2 \mathrm{~m}$, it was not easy to detect and analyze the laser signal due to the low power of seed laser. Then, the seed laser was incidented into an amplifier, composed of a pump source (Pump 2, $980 \mathrm{~nm}$ ) and a certain length EDF. Finally, the amplified laser beam propagated along a Fabry-Perot Scanning Interferometer (FPSI, Thorlabs, SA200-12B, free spectral range of $1.5 \mathrm{GHz}$, resolution of $7.5 \mathrm{MHz}$ ) through a pigtail fiber for inspecting the single-frequency characteristics. Besides, the linewidth was investigated by a delayed self-homodyne (DSH) technique, which has a delay line of $50 \mathrm{~km}$ and a frequency shifter of $200 \mathrm{MHz}$. The signal was detected by a high-speed photodetector (EOT, ET-5000F), and presented in a radio frequency spectrum analyzer (RFSA, Rigol, DSA815).

To keep the laser in a peak power output, the power of Pump 1 and Pump 2 were both set at a appropriate value, and the two PCs in the loop were also adjusted. Before MXene core-shell nanostructure solution was dripped over the taper fiber, the FPSI recorded the scanning spectrum as shown in Figure 10 by pink curve. This result indicated that the laser was operated at a multi-frequencies state, and never disappeared even though the three PCs were adjusted. Figure 11 presents the laser beam gets through the DSH system with pink curve, whose heterodyne output signal of the laser was obtained from nonsolution state. As depicted, a number of unstable peaks can be observed in the range of $0 \sim 400 \mathrm{MHz}$, which was due to the multi-frequencies. As the $\mathrm{Ti}_{2} \mathrm{C} @ \mathrm{Au}$ solution was added to the tapered fiber, the counter propagating beam created a standing wave, and established an instantaneous grating in the intra-loop simultaneously [47]. After a while, the signal on scanning spectrum turned into the blue curve, which is shown in Figure 10. Despite the multi-frequencies state was unaltered, the number of frequencies was decreased obviously. It can be imagined that the amount of frequencies measured by DSH will decline as well.

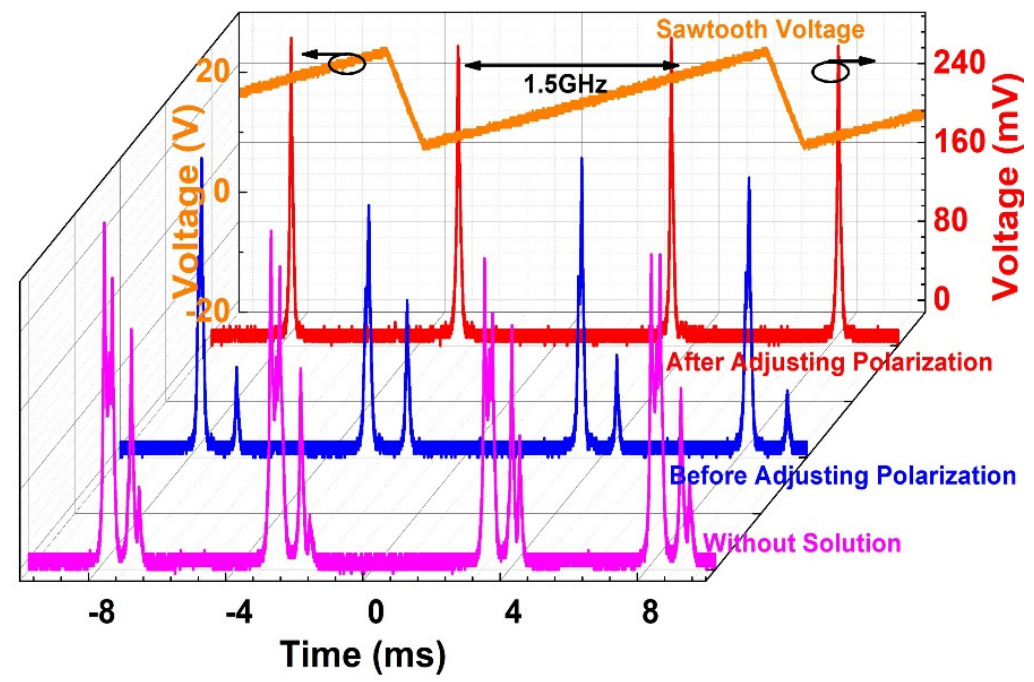

Figure 10. Evolution of FPSI scanning spectrum.

Figure 11 validates our prediction by the blue curve. We insisted that this phenomenon was induced by the SHB effect. To elimate the SHB effect, we carefully rotated the PC1, and the reflection of loop mirror was also optimized by adjusting PC2 and PC3 patiently. As a result, a typical scanning spectrum of SFFLs was achieved, which is presented in Figure 10 by the red curve. It suggested that the laser was just operated at a single frequency state, and a single peak centered at $200 \mathrm{MHz}$ appeared in the RFSA, which is shown in Figure 11 by the red curve. 


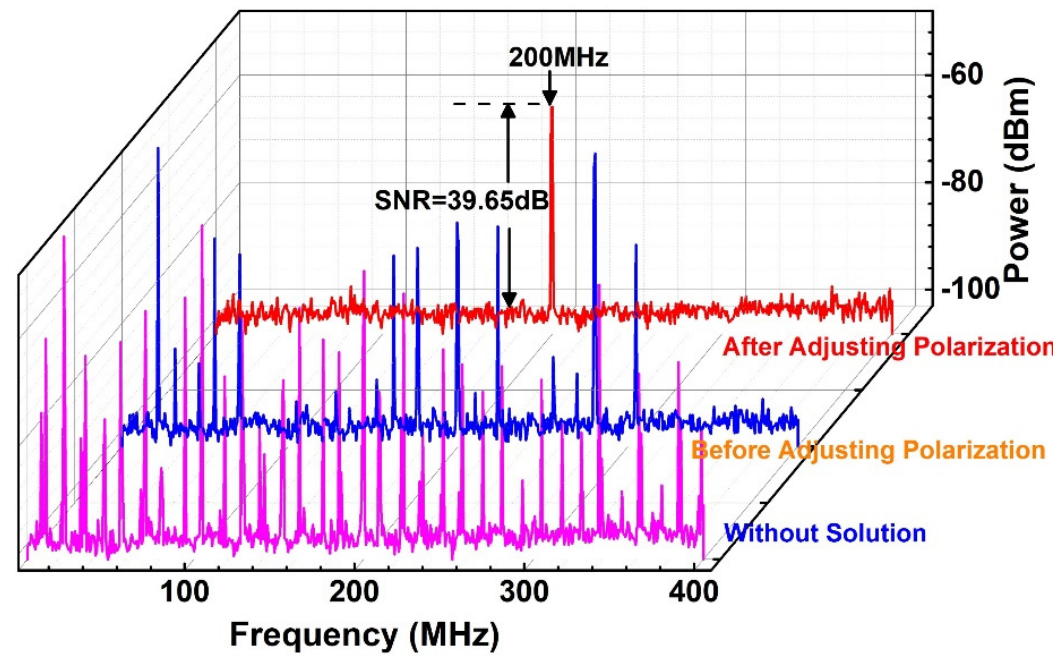

Figure 11. Evolution of FR scanning spectrum.

For investigating the linewidth of this SFFL, the frequency signal ranging from 198 to $202 \mathrm{MHz}$ was obtained by the DSH technique and the RFSA with a resolution of $600 \mathrm{~Hz}$, then fitted by Lorentzian curve, whose result is shown in Figure 12a. It is suggested that the bandwidth of the peak at $-20 \mathrm{~dB}$ was $20.63 \mathrm{kHz}$ by the fitted curve, whose result coincided with a laser with a linewidth of $1.0315 \mathrm{kHz}$.
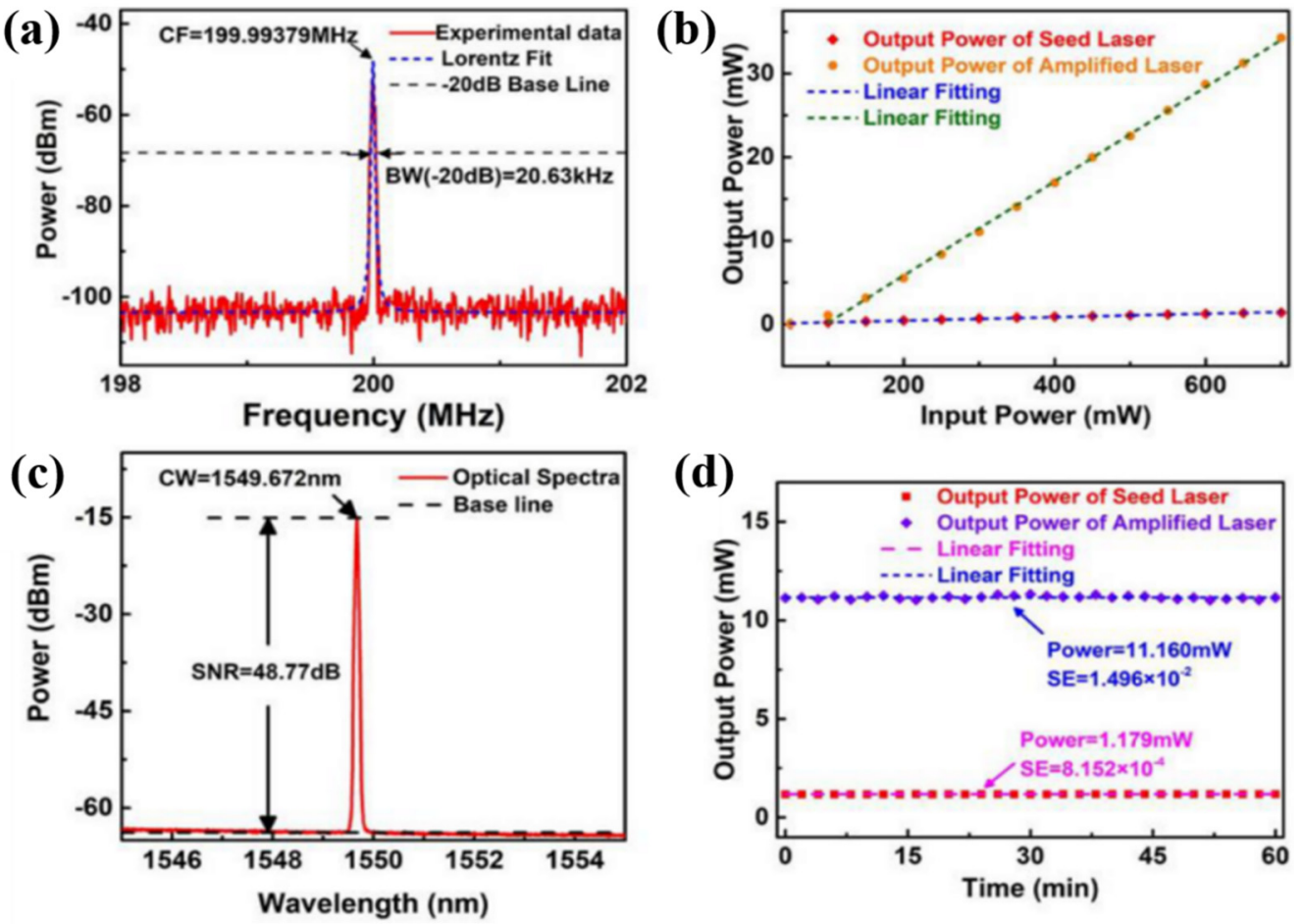

Figure 12. The spectrum measured by DSH technique and the Lorentz fit (a); the optical spectrum of amplified laser (b); output power of seed laser and amplified laser versus to input pump power (c); the output power stability of seed laser and amplified laser in $1 \mathrm{~h}(\mathbf{d})$.

Afterward, we adjusted two pump power to research the relationship between pump power and output power. First, the Pump1 power was kept under $85 \mathrm{~mW}$ until the laser stops operating. Then, the frequency signal of the laser gets unstable, and the mode became conspicuous when Pump 1 power was higher than $500 \mathrm{~mW}$. Second, we fixed the Pump1 power at $500 \mathrm{~mW}$ for the highest output power with single frequency operation, and the 
Pump 2 power was also altered from 50 to $700 \mathrm{~mW}$. Figure $12 \mathrm{~b}$ shows the output power of seed laser versus pump1 power, as well as the output power of amplified laser versus pump 2 power, and the results were fitted by line as well. A slop efficiency of $\sim 0.207 \%$ for the seed laser, and $\sim 5.64 \%$ for the amplified laser were calaculated. We believed that the short gain medium and the unsaturable loss of materials, contributed to the low slop efficiency. An optical spectrum analyzer (OSA, YOKOGAWA AQ6370D) was employed to analyze the SNR, which reached to the highest value when the Pump 2 power was locked at $300 \mathrm{~mW}$. Figure 12c exhibits that the SNR exceeded $48 \mathrm{~dB}$. In this situation, the output power of seed laser and amplified laser were recorded every two minutes within $1 \mathrm{~h}$, and the results are shown in Figure 12d. It indicated that the power of seed laser, as well as the amplified laser, had a fluctuation in the range of $1.179 \pm 0.009 \mathrm{~mW}$ and $11.17 \pm 0.15 \mathrm{~mW}$, showing that the results support the stability of less than $0.76 \%$ and $1.34 \%$ respectively. In addition, the average powers were calculated to be $1.179 \mathrm{~mW}$ and $11.160 \mathrm{~mW}$, the stability of laser power was evaluated by the standard error (SE), with values $\sim 8.152 \times 10^{-4}$ and $1.496 \times 10^{-2}$ respectively. As far as we are concerned, the increasing of power and the amplified spontaneous emission (ASE), should be accountable for the deteriorated output power stability of amplified laser.

For a convenient comparision, we listed the properties of SFFLs based on LCLM with 2D material in Table S2, it can be found that our work was reported to be the narrowest linewidth among this kind of SFFL, whose comparison is shown in supporting information.

\section{Conclusions}

In conclusion, we successfully synthesized a core-shell nanostructure composed of $\mathrm{Ti}_{2} \mathrm{C}$ (MXene) phase and gold nanoparticle. The morphology and composition were characterized by SEM, TEM, and XPS, the optoelectronic characteristic was analyzed by UV-vis spectrum and Raman spectra. The results suggested that full utilization of surface plasmon effect was made by gold nanoparticle, and attributed to the application of nonlinear optics. Finally, we applied such core-shell nanostructure to a passive modelocked EDFL and an EDF-SFFL. The results suggested that stable passive mode-locked EDFL has a low startup threshold, and approximately $410 \%$ lower than the previously reported. The pulse duration and the center wavelength of this laser were measured to be $670 \mathrm{fs}$ and $1560 \mathrm{~nm}$ respectively. The stabilized EDF-SFFL based on a linear cavity with a loop mirror embedded in a taper fiber, has a linewidth of $\sim 1.00 \mathrm{kHz}$ when immersed in such $\mathrm{Ti}_{2} \mathrm{C} @ \mathrm{Au}$ core-shell material. To our best knowledge, this was the narrowest linewidth of the SFFL based on 2D materials. It has a SNR of $31.82 \mathrm{~dB}$, and an average output power of $\sim 1.18 \mathrm{~mW}$ and $\sim 11.16 \mathrm{~mW}$ before and after amplification respectively. While, the output power fluctuation of seed laser and amplified laser was less than $0.76 \%$ and $1.34 \%$ respectively. It proved that the $\mathrm{Ti}_{2} \mathrm{C} @ \mathrm{Au}$ core-shell material can be employed to suppress the bandwidth and enhance the stability of SFFL. We believe that the passive MLFL and SFFL can be improved further by optimizing the $\mathrm{Ti}_{2} \mathrm{C} @ \mathrm{Au}$ core-shell material.

Supplementary Materials: The supplementray materials are available online at https:/ / www.mdpi. com/article/10.3390/nano11081995/s1, or obtained from the authors. Table S1: Output performance comparison of mode-locked fiber lasers using various 2D materials SAs at a wavelength of $1.55 \mu \mathrm{m}$; Table S2: Progress of SFFLs based on LCLM with 2D material.

Author Contributions: Q.W., conceived the project and designed the experiments. Y.W., S.L., F.Z., and Y.G. performed the experiments. All authors analyzed the data and discussed the experimental plans. Y.W., S.L. and F.Z. wrote the manuscript, and all authors commented on and revised it. Q.W. supervised the whole project. All authors have read and agreed to the published version of the manuscript.

Funding: This work was partly financed by the Science and Technology Innovation Commission of Shenzhen Municipality (SGDX20190919094803949, JCYJ20200109105810074 and JCYJ20170412111625378).

Institutional Review Board Statement: The study was conducted according to the guidelines of the Declaration of Helsinki, and approved by the Institutional Review Board. 
Data Availability Statement: Data underlying the results presented in this paper are not publicly available at this time but may be obtained from the authors upon reasonable request.

Acknowledgments: We acknowledge that Shenzhen university provided the experimental instruments or setups and the operation staffs who helped with the examination and tests in our work.

Conflicts of Interest: The authors declare no conflict of interest.

\section{References}

1. Naguib, M.; Come, J.; Dyatkin, B.; Presser, V.; Taberna, P.L.; Simon, P.; Barsoum, M.W.; Gogotsi, Y. MXene: A promising transition metal carbide anode for lithium-ion batteries. Eletrochem. Commun. 2012, 16, 61-64. [CrossRef]

2. $\mathrm{Hu}, \mathrm{Z} . ; \mathrm{Wu}, \mathrm{Z} . ; \mathrm{Han}, \mathrm{C}$; He, J.; Ni, Z.; Chen, W. Two-dimensional transition metal dichalcogenides: Interface and defect engineering. Chem. Soc. Rev. 2018, 47, 3100-3128. [CrossRef]

3. Lv, W.; Yang, B.; Wang, B.; Wan, W.; Ge, Y.; Yang, R.; Hao, C.; Xiang, J.; Zhang, B.; Zeng, Z. Interfaces, Sulfur-doped black phosphorus field-effect transistors with enhanced stability. ACS Appl. Mater. 2018, 10, 9663-9668. [CrossRef]

4. Nakamura, S. InGaN/GaN/AlGaN-based laser diodes grown on epitaxially laterally overgrown GaN. J. Mater. Res. 2018, 14, 2716-2731. [CrossRef]

5. Yang, Z.; Lustig, E.; Harari, G.; Plotnik, Y.; Lumer, Y.; Bandres, M.A.; Segev, M. Mode-locked topological insulator laser utilizing synthetic dimensions. Phys. Rev. X. 2020, 10, 011059. [CrossRef]

6. Hong, Q.L.; Chen, X.Q.; Zhang, J.F.; Zhu, Z.H.; Qin, S.Q. Remarkably high-Q resonant nanostructures based on atomically thin two-dimensional materials. Nanoscale 2020, 11, 23149-23155. [CrossRef]

7. Han, S.C.; Wu, L.H.; Jia, C.Y.; Li, N.; Jia, C.L.; Xue, P.; Zhang, H.; Zhao, H.B.; Ni, D.R.; Xiao, B.L.; et al. Achieving a strong polypropylene/aluminum alloy friction spot joint via a surface laser processing pretreatment. J. Mater. Sci. Tech. 2020, 50, 103-114. [CrossRef]

8. Fujieda, I.; Itaya, S.; Ohta, M.; Hirai, Y.; Kohmoto, T. Energy-harvesting laser phosphor display and its design considerations. J. Photonics Energy 2017, 7, 028001. [CrossRef]

9. Livache, C.; Martinez, B.; Goubet, N.; Gréboval, C.; Qu, J.; Chu, A.; Royer, S.; Ithurria, S.; Silly, M.G.; Dubertret, B. A colloidal quantum dot infrared photodetector and its use for intraband detection. Nat. Commun. 2019, 10, 2125. [CrossRef]

10. Yang, Y.; Jeon, J.; Park, J.H.; Jeong, M.S.; Lee, B.H.; Hwang, E.; Lee, S. Plasmonic transition metal carbide electrodes for high-performance InSe photodetectors. ACS Nano 2019, 13, 8804-8810. [CrossRef] [PubMed]

11. Alayat, M.S.; Aly, T.H.; Elsayed, A.E.; Fadil, A.S. Correction to: Efficacy of pulsed Nd: YAG lasers in the treatment of patients with knee osteoarthritis: A randomized controlled trial. Lasers Med. Sci. 2020, 35, 1875. [CrossRef]

12. Oliveira, Y.D.; Amurin, L.G.; Valim, F.C.; Fechine, G.J.; Andrade, R.J. The role of physical structure and morphology on the photodegradation behaviour of polypropylene-graphene oxide nanocomposites. Polymer 2019, 176, 146-158. [CrossRef]

13. Castellanos-Gomez, A.; Vicarelli, L.; Prada, E.; Island, J.O.; Narasimha-Acharya, K.; Blanter, S.I.; Groenendijk, D.J.; Buscema, M.; Steele, G.A.; Alvarez, J. Isolation and characterization of few-layer black phosphorus. 2D Mater. 2014, 1, 025001. [CrossRef]

14. Ding, L.; Wei, Y.; Li, L.; Zhang, T.; Wang, H.; Xue, J.L.; Ding, L.X.; Wang, S.; Caro, J.; Gogotsi, Y. MXene molecular sieving membranes for highly efficient gas separation. Nat. Commun. 2018, 9, 155. [CrossRef] [PubMed]

15. Jiang, X.; Liu, S.; Liang, W.; Luo, S.; He, Z.; Ge, Y.; Wang, H.; Cao, R.; Zhang, F.; Wen, Q. Broadband Nonlinear Photonics in Few-Layer MXene $\mathrm{Ti}_{3} \mathrm{C}_{2} \mathrm{Tx}(\mathrm{T}=\mathrm{F}, \mathrm{O}$, or OH). Laser Photonics Rev. 2018, 12, 1700221-1700229.

16. Dong, Y.; Chertopalov, S.; Maleski, K.; Anasori, B.; Hu, L.; Bhattacharya, S.; Rao, A.M.; Gogotsi, Y.; Mochalin, V.N.; Podila, R. Saturable Absorption in 2D Ti ${ }_{3} C_{2}$ MXene Thin Films for Passive Photonic Diodes. Adv. Mater. 2018, 30, 1705711-1705718. [CrossRef] [PubMed]

17. Xie, Y.; Dall'Agnese, Y.; Naguib, M.; Gogotsi, Y.; Barsoum, M.W.; Zhuang, H.L.; Kent, P.R. Prediction and characterization of Mxene nanosheet anodes for non-lithum-ion batteries. ACS Nano 2014, 8, 9605-9613. [CrossRef] [PubMed]

18. Ling, Z.; Ren, C.E.; Zhao, M.Q.; Yang, J.; Giammarco, J.M.; Qiu, J.; Barsoum, M.W.; Gogotsi, Y. Flexible and conductive MXene films and nanocomposites with high capacitance. Proc. Natl. Acad. Sci. USA 2014, 111, 16676-16681. [CrossRef]

19. Ran, J.; Gao, G.; Li, F.T.; Ma, T.Y.; Du, A.; Qiao, S.Z. $\mathrm{Ti}_{3} \mathrm{C}_{2}$ MXene co-catalyst on metal sulfide photo-absorbers for enhanced visible-light photocatalytic hydrogen production. Nat. Commun. 2017, 8, 13907. [CrossRef]

20. Zhang, X.; Zhang, Z.; Zhou, Z. MXene-based materials for electrochemical energy storage. J. Energy Chem. 2018, 27, 73-85. [CrossRef]

21. Zhu, J.; Yu, Z.; Burkhard, G.F.; Hsu, C.M.; Connor, S.T.; Xu, Y.; Wang, Q.; McGehee, M.; Fan, S.; Cui, Y. Optical absorption enhancement in amorphous silicon nanowire and nanocone arrays. Nano Lett. 2009, 9, 279-282. [CrossRef] [PubMed]

22. Ma, Z.; Kang, S.; Ma, J.; Shao, L.; Zhang, Y.; Liu, C.; Wei, A.; Xiang, X.; Wei, L.; Gu, J. Ultraflexible and Mechanically Strong DoubleLayered Aramid Nanofiber- $\mathrm{Ti}_{3} \mathrm{C}_{2} \mathrm{Tx}$ MXene/Silver Nanowire Nanocomposite Papers for High-Performance Electromagnetic Interference Shielding. ACS Nano 2020, 14, 8368-8382. [CrossRef] [PubMed]

23. Li, K.; Jiao, T.; Xing, R.; Zou, G.; Zhao, Q.; Zhou, J.; Zhang, L.; Peng, Q. Fabrication of hierarchical MXene-based AuNPs-containing core-shell nanocomposites for high efficient catalysts. Green Energy Environ. 2018, 3, 147-155. [CrossRef] 
24. Tang, W.; Dong, Z.; Zhang, R.; Yi, X.; Yang, K.; Jin, M.; Yuan, C.; Xiao, Z.; Liu, Z.; Cheng, L. Multifunctional two-dimensional core-shell mxene@ gold nanocomposites for enhanced photo-radio combined therapy in the second biological window. ACS Nano 2018, 13, 284-294. [CrossRef]

25. Ali, W.; Mideksa, M.F.; Hou, K.; Li, H.; Wang, X.; Tang, Z. All-Solution-Processed Ultrahigh Broadband and Wide-Angle Perfect Absorber Based on Mxene-Gold Nanoparticles. Adv. Opt. Mater. 2020, 8, 2000447-2000454. [CrossRef]

26. Gillner, A.; Holtkamp, J.; Hartmann, C.; Olowinsky, A.; Gedicke, J.; Klages, K.; Bosse, L.; Bayer, A.J.J. Laser applications in microtechnology. J. Mater. Process. Technol. 2005, 167, 494-498. [CrossRef]

27. Gattass, R.R.; Mazur, E. Femtosecond laser micromachining in transparent materials. Nat. Photonics 2008, 2, 219-225. [CrossRef]

28. Chung, S.H.; Mazur, E. Surgical applications of femtosecond lasers. J. Biophotonics 2009, 2, 557-572. [CrossRef]

29. Pan, D.; Ke, C.; Fu, S.; Liu, Y.; Liu, D.; Willner, A.E. All-optical spectral linewidth reduction of lasers for coherent optical communication. Optics Lett. 2013, 38, 5220-5223. [CrossRef]

30. Diaz, S.; Abad, S.; Lopez-Amo, M.J. Fiber-optic sensor active networking with distributed erbium-doped fiber and Raman amplification. Laser Photonics Rev. 2008, 2, 480-497. [CrossRef]

31. Adhikari, R.X. Gravitational radiation detection with laser interferometry. Rev. Mod. Phys. 2014, 86, 121-127. [CrossRef]

32. Yang, F.; Ye, Q.; Pan, Z.; Chen, D.; Cai, H.; Qu, R.; Yang, Z.; Zhang, Q. 100-mW linear polarization single-frequency all-fiber seed laser for coherent Doppler lidar application. Opt. Commun. 2012, 285, 149-152. [CrossRef]

33. Passy, R.; Gisin, N.; Von Der Weid, J.P.; Gilgen, H. Experimental and theoretical investigations of coherent OFDR with semiconductor laser sources. J. Lightwave Technol. 1994, 12, 1622-1630. [CrossRef]

34. Xu, N.; Li, H.; Gan, Y.; Chen, H.; Li, W.; Zhang, F.; Jiang, X.; Shi, Y.; Liu, J.; Wen, Q.; et al. Zero-Dimensional MXene-Based Optical Devices for Ultrafast and Ultranarrow Photonics Applications. Adv. Sci. 2020, 7, 2002209-2002215. [CrossRef]

35. Gan, Y.; Zhu, F.; Shi, Y.; Wen, Q. Single frequency fiber laser base on MXene with kHz linewidth. J. Mater. Chem. C 2021, 9 , 2276-2281. [CrossRef]

36. Ooka, H.; Nakamura, R. Shift of the optimum binding energy at higher rates of catalysis. J. Phys. Chem. Lett. 2019, 10, 6706-6713. [CrossRef] [PubMed]

37. Greczynski, G.; Hultman, L. X-ray photoelectron spectroscopy: Towards reliable binding energy referencing. Prog. Mater. Sci. 2020, 107, 100591-100637. [CrossRef]

38. Johansson, B.; Mårtensson, N. Core-level binding-energy shifts for the metallic elements. Phys. Rev. B 1980, $21,4427-4434$. [CrossRef]

39. EI-Demellawi, J.K.; Lopatin, S.; Yin, J.; Mohammed, O.F.; Alsharref, H.N. Tunable multipolar surface plasmons in 2D Ti ${ }_{3} \mathrm{C}_{2} \mathrm{Tx}$ Mxene flakes. ACS Nano 2018, 12, 8485-8493. [CrossRef]

40. Liu, Y.; Zhou, T.; Zheng, Y.; He, Z.; Xiao, C.; Pang, W.K.; Tong, W.; Zou, Y.; Pan, B.; Guo, Z. Local electric field facilitates high-performance Li-ion batteries. ACS Nano 2017, 11, 8519-8526. [CrossRef]

41. Faryad, M. Differentiating surface plasmon-polariton waves and waveguide modes guided by interfaces with one-dimensional photonic crystals. Appl. Phys. A 2018, 124, 102. [CrossRef]

42. Farmani, A.; Miri, M.; Sheikhi, M.H. Design of a high extinction ratio tunable graphene on white graphene polarizer. IEEE Photonics Technol. Lett. 2017, 30, 153-156. [CrossRef]

43. Woldemariam, M.M. Nonlinear absorption coefficient and refractive index changes of two-dimensional two-electron quantum dot in rigid confinement. Int. J. Mod. Phys. B 2019, 33, 1950078. [CrossRef]

44. Tuo, M.; Xu, C.; Mu, H.; Bao, X.; Wang, Y.; Xiao, S.; Ma, W.; Li, L.; Tang, D.; Zhang, H. Ultrathin 2D transition metal carbides for ultrafast pulsed fiber lasers. Phys. Rev. Lett. 2018, 5, 1808-1816. [CrossRef]

45. Krishnakanth, K.N.; Seth, S.; Samanta, A.; Rao, S.V. Broadband ultrafast nonlinear optical studies revealing exciting multi-photon absorption coefficients in phase pure zero-dimensional $\mathrm{Cs}_{4} \mathrm{PbBr}_{6}$ perovskite films. Nanoscale 2019, 11, 945-954. [CrossRef] [PubMed]

46. Huang, S.; Qin, G.; Feng, Y.; Shirakawa, A.; Musha, M.; Ueda, K.I. Single-frequency fiber laser from linear cavity with loop mirror filter and dual-cascaded FBGs. IEEE Photonics Technol. Lett. 2005, 17, 1169-1171. [CrossRef]

47. Havstad, S.A.; Fischer, B.; Willner, A.E.; Wickham, M.G. Loop-mirror filters based on saturable-gain or-absorber gratings. Opt. Lett. 1999, 24, 1466-1468. [CrossRef] [PubMed] 